\title{
Organizational and technological compatibility of the technological processes of second and third line maintenance of KhTZ-3522 tractors
}

\author{
Roman Kyzminskyj ${ }^{1}$, Ruslan Barabash $^{1}$ \\ ${ }^{1}$ Lviv National Agrarian University, St. Vladimir the Great 1, 80381, Dubliany, Ukraine
}

\begin{abstract}
The work is devoted to systematic substantiation of productivity, production structure and specialization of service stations of KhTZ-3522 tractors. Based on the technical and economic comparative analysis of the results of the technological processes modeling of the second and third line maintenance of KhTZ-3522 tractors, the parametrical series of production structures of service stations both mono- and polytechnological specialization, which can work effectively in a wide range of the general annual program of orders, and in the conditions of seasonal fluctuations of orders for the maintenance of these tractors, are found. The results of calculations of the indicators system for organizational and technological compatibility of technological processes of the second and third line maintenance of KhTZ-3522 tractors in the joint technological flow are presented. The dependencies of these indicators on the total annual program of orders for service stations of different productivity are analyzed. According to the results of the analysis, the polytechnological specialization of such service stations is substantiated.
\end{abstract}

\section{Introduction}

Tractors of Kharkiv Tractor Plant (KhTZ) are among the most common in Ukraine. In addition to well-known brands such as KhTZ-150K-09 (drawbar category - 3,0), KhTZ began production of new tractors, in particular KhTZ-3510 (drawbar category - 0,9) and KhTZ-3522 (drawbar category -1,4), which are intended mainly for small farms.

Efficient use of these new brands of tractors involves timely and qualitative maintenance. First (service interval -250 hours), second (service interval -500 hours) and third (service interval - 1000 hours) line maintenance are provided by the manufacturer for these tractors. The list of operations for each type of maintenance is determined by the manufacturer $[1,2]$. The operations of each previous line maintenance are included in the following line maintenance. Real first line maintenance are performed by tractor drivers directly at the place of tractors operation. In order to perform operations of second line maintenance of KhTZ3522 tractors, there is need to use 14 different types of special equipment and tools $(r=14)$, and to perform operations of third line maintenance - 15 different types $(r=15)$. Therefore, qualified masters at stationary posts of service stations must carry out these complex types of maintenance [3, 4].

However, the technical service base for these new KhTZ tractor brands has not yet been created in Ukraine.
An effective performance of maintenance service on a long-term basis leads to developing loyalty of the client to the company [5]. Technical service is of primary importance in building the client's satisfaction. It should be performed by highly qualified staff and the logistic system of the service should be suited for effective realization of orders placed by users [6].

The substantiation of the program $W_{A}$, the performance $Q_{A}$, the production structure and the specialization of the technical service enterprises are complex system tasks [7], which involve the use of an iterative procedure for the solution of interdependent parametric and structural optimization tasks [8].

Regarding the technical service processes performed on stationary posts, the task of substantiating their parameters and structure was for the first time solved using the graph theory and schedules for the technological processes of the current repair of tractors [9], but the interdependence between all parameters and performance indicators of the technological process was not taken into account. The application of the iteration procedure has made it possible to eliminate this defect in relation to the tasks of determining the parameters and indicators of efficiency of the technological processes of maintenance of KhTZ tractors [10], as well as the substantiation of the production structure of the service stations of KhTZ tractors [11, 12].

The ground for the determination of specialization of selected production units of the technical service enterprises is organizational and technological

\footnotetext{
${ }^{*}$ Corresponding author: rkuzminsky@gmail.com
} 
compatibility (OTC) of the processes performed there [13]. The property of the OTC is determined by the similarity of the construction design of the machines and the technology of the work, the flexibility of the equipment used, and also depends on the overall annual program of work (general program), and on the quantitative proportion of various processes (partial programs) in the general program. If for a certain value of a general program and a certain proportion of partial programs, the cost of implementing different processes in the joint flow is less than the cost of implementing the same processes separately, then it is considered to be OTC of these processes.

In the case of OTC of the different technological processes, a multidisciplinary or polytechnological specialization is appropriate.

For the quantitative assessment of the properties of the OTC, the system of indicators with a certain technical, technological and production content is used [14].

An assumption was made that any ratio of partial programs of orders for different types of technical maintenance in the total program of orders $W_{A}$ min is equally probable. Then the coefficient of OTC $\alpha_{W}$ - is the probability of the occurrence of such ratio of partial programs for which the costs for different types of maintenance in the joint flow on SS of polytechnological specialization are less than the costs of implementing the same processes separately on different SSs of monotechnological specialization. Then also the coefficient level of OTC $\beta_{W}$ - is the probability of obtaining for a considerable period of time $T$ such a cost benefit from joining technological processes of different types of maintenance in the joint flow. If only such ratios of partial programs of orders for different types of technical maintenance in the total program of orders $W_{A}$ ${ }_{\min }$ are taken into account, for which the OTC exists, then the coefficient relative level of OTC $\gamma_{W}$-identifies the ratio between the cost benefit from joining technological processes of different types of maintenance in the joint flow on SS of polytechnological specialization and the total costs for maintenance in the joint flow. The method [15] for calculating these indices has been developed in advance.

The objective of the work is to increase the efficiency of the technical service of the KhTZ-3522 tractors by way of substantiation of the specialization (mono- or polytechnological) of branded service stations of different capacity and production structure from the corresponding parametric series.

\section{Methodology}

According to the results of modeling of the technological processes of second and third line maintenance of KhTZ3522 tractors using the theory of graphs and heuristic algorithms of the theory of schedules and analysis of the mutual dependencies between different parameters and performance indicators of these processes [12], the set of possible different variants of production structures of service stations, which provide the same annual $Q_{A}$. capacity, has been synthesized.

The feasibility and economic comparison of various possible options was made on the basis of the total expenditure for the entire annual maintenance program $\Sigma Z$. The total expenditure $\Sigma Z$ included the costs determined by the production structure of the service station $Z_{S S}$ (wages of workers, allowance for keeping and depreciation of equipment and industrial premises, payment for power electric etc.), and also the costs which are determined by the technology of performance $Z_{l m}$ (costs for fuel, lubricants and other process materials etc.). The arrangement of the comparison results made it possible to form parametric series of service stations for KhTZ-3522 tractors (Table 1, 2) with different production structure and capacity of monotechnological specialization (for the performance of only second or only third line technical maintenance respectively). The optimal capacity for each maintenance item from the parametric series was determined by the criterion for minimizing specific costs $\left(C=\Sigma \mathrm{Z} / Q_{A}\right) \rightarrow \min$.

\section{Results and discussion}

To the parametric series of service stations for the second line maintenance of KhTZ-3522 tractors (Table 1) five different variants of production structures have been included, that differ in the number of equipment of individual types (high-pressure jet cleaners Karcher K5 Compact $K_{r 1}$, mobile machines Flexbimec-5903 for washing parts $K_{r 6}$ and universal devices C-230 for oiling $\left.K_{r 7}\right)$ the number of stationary posts $f$, and, consequently, the production area. The list of all other types of required equipment for the second line maintenance of KhTZ3522 tractors is determined by the technology of work $[1,2]$. Since all other types of necessary equipment are intended to perform only one operation, the number of equipment of all other types $K_{r}=1 \mathrm{pcs}$.

The capacity of each variant of the production structure of the technical service station may vary within a sufficiently wide range, depending on the number of employees engaged, which enables the adaptation of service station performance to seasonal variations in the number of orders (Table 1,2).

For example, the first variant of the production structure of the service stations for the second line maintenance of KhTZ-3522 tractors can provide maximum annual capacity $Q_{A}=896$ orders per year, if the number of workers is $u=4$ persons. If the number of workers is $u=1$ person, then annual capacity will be only $Q_{A}=296$ orders per year. For this production structure, optimal performance that meets the minimum specific costs is 799 orders per year, when three workers work ( $u=3$ persons). The second variant of the production structure of the service station for the second line maintenance of KhTZ-3522 tractors is characterized by an increase in the number of equipment (highpressure jet washing machines Karcher K5 Compact $K_{r 1}=4$ pcs, mobile machines Flexbimec $-5903 K_{r 6}=2$ pcs and universal devices C-230 for filling oil $K_{r 7}=2 \mathrm{pcs}$ ). This variant can provide maximum annual capacity $Q_{A}=$ 
$=1040$ orders per year, if the number of workers is $u=8$ persons. For this production structure, optimal performance is a bit bigger and it is 877 orders per year, when three workers work ( $u=3$ persons).

The next three variants of the production structure of the service stations for the second line maintenance of KhTZ-3522 tractors are characterized by an increase in the number of posts $f$ and working area respectively. Each next variant has a wider range of productivity changes by attracting a different number of workers. The optimal performance of each next variant is also higher than the previous one and it is achieved for an evergreater number of workers.

To the parametric series of service stations for the third line maintenance of KhTZ-3522 tractors (Table 2) also includes five different variants of production structures. These variants are very similar to the corresponding variants of production structures of service stations for the second line maintenance of KhTZ-3522 tractors and differ only in the use of additional type of equipment $(r=15)$ - the testing bench of tractor electrical equipment group SKIF-1-03. However, it should be noted that for similar variants of the production structure, the maximum and optimal values of annual capacity of service stations for the third line maintenance of KhTZ-3522 tractors are significantly lower than the corresponding values of service stations for the second line maintenance.

Table 1. The parametric series of service stations with different production structure and capacity for the second line maintenance of KhTZ-3522 tractors.

\begin{tabular}{|c|c|c|c|c|c|c|c|c|c|c|}
\hline \multirow{2}{*}{$\begin{array}{c}\text { №o } \\
\text { f } \\
\text { SS }\end{array}$} & \multirow{2}{*}{$\begin{array}{c}\text { Annual } \\
\text { capacity } \\
Q_{\mathrm{A}}, \\
\text { orders }\end{array}$} & \multicolumn{3}{|c|}{$\begin{array}{c}\text { Amount of equipment } \\
\text { and tools*, pes. }\end{array}$} & \multirow{2}{*}{$\begin{array}{c}\text { Number of } \\
\text { posts } \\
f \text {, units }\end{array}$} & \multirow{2}{*}{$\begin{array}{l}\text { Number of } \\
\text { workers } \\
u \text {, persons }\end{array}$} & \multicolumn{4}{|c|}{ Economic indicators } \\
\hline & & $K_{r 1}$ & $K_{r 6}$ & $\boldsymbol{K}_{r 7}$ & & & $\begin{array}{l}Z_{S S} \\
\mathrm{UAH}\end{array}$ & $\begin{array}{l}Z_{l-m}, \\
\mathrm{UAH}\end{array}$ & $\begin{array}{c}\Sigma Z \\
\mathrm{UAH}\end{array}$ & $\begin{array}{c}C, \\
\text { UAH }\end{array}$ \\
\hline \multirow{4}{*}{ I } & 296 & \multirow{4}{*}{1} & \multirow{4}{*}{1} & \multirow{4}{*}{1} & \multirow{4}{*}{1} & 1 & 117475 & 1844719 & 1962194 & 6629,03 \\
\hline & 562 & & & & & 2 & 165475 & 3502474 & 3667949 & 6526,6 \\
\hline & $799^{\text {opt }}$ & & & & & $3^{\mathrm{opt}}$ & 213475 & 4979496 & 5192971 & 6499,34 \\
\hline & 896 & & & & & 4 & 261475 & 5584015 & 5845490 & 6523,98 \\
\hline \multirow{4}{*}{ II } & 296 & \multirow{4}{*}{4} & \multirow{4}{*}{2} & \multirow{4}{*}{2} & \multirow{4}{*}{1} & 1 & 126168 & 1844719 & 1970887 & 6658,4 \\
\hline & 593 & & & & & 2 & 174168 & 3695671 & 3869839 & 6525,87 \\
\hline & $877^{\mathrm{opt}}$ & & & & & $3^{\mathrm{opt}}$ & 222168 & 5465604 & 5687772 & 6485,49 \\
\hline & 1040 & & & & & 4 & 270168 & 6481446 & 6751614 & 6491,94 \\
\hline \multirow{8}{*}{ III } & 296 & \multirow{8}{*}{4} & \multirow{8}{*}{2} & \multirow{8}{*}{2} & \multirow{8}{*}{2} & 1 & 138516 & 1844719 & 1983236 & 6700,12 \\
\hline & 605 & & & & & 2 & 186516 & 3770457 & 3956973 & 6540,45 \\
\hline & 903 & & & & & 3 & 234516 & 5627640 & 5862157 & 6491,87 \\
\hline & 1217 & & & & & 4 & 282516 & 7584539 & 7867055 & 6464,3 \\
\hline & $1522^{\mathrm{opt}}$ & & & & & $5^{\text {opt }}$ & 330516 & 9485348 & 9815864 & 6449,32 \\
\hline & 1739 & & & & & 6 & 378516 & 10837726 & 11216243 & 6449,82 \\
\hline & 1916 & & & & & 7 & 426516 & 11940819 & 12367335 & 6454,77 \\
\hline & 2049 & & & & & 8 & 474516 & 12769696 & 13244212 & 6463,74 \\
\hline \multirow{10}{*}{ IV } & 296 & \multirow{10}{*}{4} & & & & 1 & 153975 & 1844719 & 1998695 & 6752,35 \\
\hline & 614 & & & & & 2 & 201975 & 3826546 & 4028522 & 6561,11 \\
\hline & 915 & & & & & 3 & 249975 & 5702426 & 5952402 & 6505,36 \\
\hline & 1217 & & & & & 4 & 297975 & 7584539 & 7882514 & 6477 \\
\hline & 1510 & & & & & 5 & 345975 & 9410562 & 9756537 & 6461,28 \\
\hline & 1784 & & 2 & 2 & 3 & 6 & 393975 & 11118173 & 11512149 & 6453 \\
\hline & 2049 & & & & & 7 & 441975 & 12769696 & 13211671 & 6447,86 \\
\hline & $2300^{\text {opt }}$ & & & & & $8^{\text {opt }}$ & 489975 & 14333968 & 14823943 & 6445,19 \\
\hline & 2493 & & & & & 9 & 537975 & 15536775 & 16074750 & 6447,95 \\
\hline & 2555 & & & & & 10 & 585975 & 15923169 & 16509144 & 6461,5 \\
\hline & 296 & & & & & 1 & 176542 & 1844719 & 2021261 & 6828,58 \\
\hline & 616 & & & & & 2 & 224542 & 3839011 & 4063552 & 6596,68 \\
\hline & 920 & & & & & 3 & 272542 & 5733587 & 6006129 & 6528,4 \\
\hline & 1224 & & & & & 4 & 320542 & 7628164 & 7948706 & 6494,04 \\
\hline & 1522 & & & & & 5 & 368542 & 9485348 & 9853889 & 6474,3 \\
\hline & 1815 & & & & & 6 & 416542 & 11311370 & 11727912 & 6461,66 \\
\hline $\mathrm{V}$ & 2090 & 4 & & & & 7 & 464542 & 13025214 & 13489756 & 6454,43 \\
\hline$V$ & 2379 & 4 & 2 & 2 & 4 & 8 & 512542 & 14826309 & 15338850 & 6447,6 \\
\hline & $2620^{\mathrm{opt}}$ & & & & & $9^{\text {opt }}$ & 560542 & 16328259 & 16888801 & 6446,11 \\
\hline & 2797 & & & & & 10 & 608542 & 17431352 & 18039893 & 6449,73 \\
\hline & 3000 & & & & & 11 & 656542 & 18696480 & 19353022 & 6451,01 \\
\hline & 3136 & & & & & 12 & 704542 & 19544054 & 20248596 & 6456,82 \\
\hline & 3234 & & & & & 13 & 752542 & 20154805 & 20907347 & 6464,86 \\
\hline & 3338 & & & & & 14 & 800542 & 20802950 & 21603492 & 6471,99 \\
\hline
\end{tabular}


Table 2. The parametric series of service stations with different production structure and capacity for the third line maintenance of KhTZ-3522 tractors

\begin{tabular}{|c|c|c|c|c|c|c|c|c|c|c|}
\hline \multirow{2}{*}{$\begin{array}{l}\text { № } \\
\text { of } \\
\text { SS }\end{array}$} & \multirow{2}{*}{$\begin{array}{c}\text { Annual } \\
\text { capacity } \\
Q_{\mathrm{A}}, \\
\text { orders }\end{array}$} & \multicolumn{3}{|c|}{$\begin{array}{l}\text { Amount of equipment } \\
\text { and tools*, pes. }\end{array}$} & \multirow{2}{*}{$\begin{array}{c}\text { Number of } \\
\text { posts } \\
f, \text { units }\end{array}$} & \multirow{2}{*}{$\begin{array}{c}\text { Number of } \\
\text { workers } \\
u \text {, persons }\end{array}$} & \multicolumn{4}{|c|}{ Economic indicators } \\
\hline & & $\kappa_{r 1}$ & $K_{r 6}$ & $\boldsymbol{K}_{r 7}$ & & & $\begin{array}{l}Z_{S S} \\
\mathrm{UAH}\end{array}$ & $\begin{array}{l}Z_{l-m}, \\
\mathrm{UAH}\end{array}$ & $\begin{array}{l}\Sigma Z, \\
\mathrm{UAH}\end{array}$ & $\begin{array}{c}C, \\
\text { UAH }\end{array}$ \\
\hline \multirow{4}{*}{ I } & 229 & \multirow{4}{*}{1} & \multirow{4}{*}{1} & \multirow{4}{*}{1} & \multirow{4}{*}{1} & 1 & 122966 & 1822650 & 1945616 & 8496,14 \\
\hline & 440 & & & & & 2 & 170966 & 3502035 & 3673001 & 8347,73 \\
\hline & $589^{\text {opt }}$ & & & & & $3^{\mathrm{opt}}$ & 218966 & 4687951 & 4906917 & 8330,93 \\
\hline & 625 & & & & & 4 & 266966 & 4974481 & 5241448 & 8386,32 \\
\hline \multirow{4}{*}{ II } & 229 & \multirow{4}{*}{4} & \multirow{4}{*}{2} & \multirow{4}{*}{2} & \multirow{4}{*}{1} & 1 & 131659 & 1822650 & 1954309 & 8534,1 \\
\hline & 458 & & & & & 2 & 179659 & 3645300 & 3824959 & 8351,44 \\
\hline & $638^{\text {opt }}$ & & & & & $3^{\text {opt }}$ & 227659 & 5077951 & 5305610 & 8316 \\
\hline & 694 & & & & & 4 & 275659 & 5523664 & 5799323 & 8356,37 \\
\hline \multirow{8}{*}{ III } & 229 & \multirow{8}{*}{4} & \multirow{8}{*}{2} & \multirow{8}{*}{2} & \multirow{8}{*}{2} & 1 & 144008 & 1822650 & 1966658 & 8588,02 \\
\hline & 464 & & & & & 2 & 192008 & 3693055 & 3885063 & 8372,98 \\
\hline & 696 & & & & & 3 & 240008 & 5539582 & 5779590 & 8304,01 \\
\hline & 936 & & & & & 4 & 288008 & 7449783 & 7737791 & 8266,87 \\
\hline & $1118^{\mathrm{opt}}$ & & & & & $5^{\mathrm{opt}}$ & 336008 & 8898352 & 9234360 & 8259,71 \\
\hline & 1254 & & & & & 6 & 384008 & 9980799 & \begin{tabular}{|l|}
10364807 \\
\end{tabular} & 8265,4 \\
\hline & 1335 & & & & & 7 & 432008 & 10625492 & \begin{tabular}{|l|}
11057500 \\
\end{tabular} & 8282,77 \\
\hline & 1408 & & & & & 8 & 480008 & 11206511 & \begin{tabular}{|l|}
11686519 \\
\end{tabular} & 8300,08 \\
\hline \multirow{10}{*}{ IV } & 229 & \multirow{10}{*}{4} & & & & 1 & 159467 & 1822650 & 1982117 & 8655,53 \\
\hline & 471 & & & & & 2 & 207467 & 3748769 & 3956236 & 8399,65 \\
\hline & 704 & & & & & 3 & 255467 & 5603256 & 5858722 & 8322,05 \\
\hline & 932 & & & & & 4 & 303467 & 7417946 & 7721413 & 8284,78 \\
\hline & 1156 & & & & & 5 & 351467 & 9200801 & 9552267 & 8263,21 \\
\hline & 1344 & & 2 & 2 & 3 & 6 & 399467 & 10697125 & \begin{tabular}{|l|}
11096591 \\
\end{tabular} & 8256,39 \\
\hline & $1533^{\mathrm{opt}}$ & & & & & $7^{\text {opt }}$ & 447467 & 12201408 & \begin{tabular}{|l|}
12648874 \\
\end{tabular} & 8251,06 \\
\hline & 1656 & & & & & 8 & 495467 & 13180386 & \begin{tabular}{|l|}
13675852 \\
\end{tabular} & 8258,36 \\
\hline & 1725 & & & & & 9 & 543467 & \begin{tabular}{|l|}
13729568 \\
\end{tabular} & \begin{tabular}{|l|}
14273035 \\
\end{tabular} & 8274,22 \\
\hline & 1815 & & & & & 10 & 591467 & 14445894 & \begin{tabular}{|l|}
15037360 \\
\end{tabular} & 8285,05 \\
\hline & 229 & & & & & 1 & 182033 & 1822650 & 2004683 & 8754,07 \\
\hline & 472 & & & & & 2 & 230033 & 3756728 & 3986761 & 8446,53 \\
\hline & 706 & & & & & 3 & 278033 & 5619174 & 5897207 & 8352,98 \\
\hline & 936 & & & & & 4 & 326033 & 7449783 & 7775816 & 8307,5 \\
\hline & 1169 & & & & & 5 & 374033 & 9304270 & 9678303 & 8279,13 \\
\hline & 1389 & & & & & 6 & 422033 & 11055287 & \begin{tabular}{|l|}
11477320 \\
\end{tabular} & 8263,01 \\
\hline $\mathrm{V}$ & 1580 & 4 & 2 & ? & 4 & 7 & 470033 & 12575489 & 13045522 & 8256,66 \\
\hline$v$ & 1739 & 4 & 2 & 2 & 4 & 8 & 518033 & 13840997 & 14359030 & 8257,06 \\
\hline & $1934^{\mathrm{opt}}$ & & & & & $9^{\text {opt }}$ & 566033 & 15393035 & 15959068 & 8251,84 \\
\hline & 2070 & & & & & 10 & 614033 & 16475482 & 17089515 & 8255,8 \\
\hline & 2178 & & & & & 11 & 662033 & 17335072 & 17997105 & 8263,13 \\
\hline & 2250 & & & & & 12 & 710033 & 17908133 & 18618165 & 8274,74 \\
\hline & 2325 & & & & & 13 & 758033 & 18505070 & 19263103 & 8285,21 \\
\hline & 2379 & & & & & 14 & 806033 & 18934865 & 19740898 & 8297,98 \\
\hline
\end{tabular}

For example, the maximum annual capacity of the third variant of the production structure of the service station for the second line maintenance of KhTZ-3522 tractors is $Q_{A}=2049$ orders per year, and the maximum annual capacity of the third variant of the production structure of the service station for the third line maintenance of KhTZ-3522 tractors is only $Q_{A}=1408$ orders per year. This significant difference is explained by the greater labor-intensive characteristic of the technological processes of the third line maintenance.
Because all operations of the second line maintenance of KhTZ-3522 tractors are also performed during the third line maintenance of these tractors, therefore the parametric series of service stations for the third line maintenance corresponds to the parametric series of the polytechnological specialization service stations of KhTZ-3522 tractors, where one can perform these two different types of technical maintenance in the joint technological flow (Table 3 ).

It should be noted, that the capacity of service stations for maintenance of KhTZ-3522 tractors of the 
polytechnological specialization depends on the ratio of orders for different types of maintenance: maximum capacity $Q_{A}$ max is reached, when all orders will be executed for only second line maintenance, but minimal capacity $Q_{A}$ min, when all orders will be for the third line maintenance only (Table 3).

Table 3. The results of calculation of indexes of organizational and technological compatibility (OTC) of second and third line maintenance for service stations with different production structure and capacity from parametric series.

\begin{tabular}{|c|c|c|c|c|c|c|c|c|c|c|}
\hline \multirow{2}{*}{$\begin{array}{l}\text { №o } \\
\text { f SS }\end{array}$} & \multicolumn{2}{|c|}{$\begin{array}{c}\text { Annual capacity } \\
\boldsymbol{Q}_{A}, \text { orders }\end{array}$} & \multicolumn{3}{|c|}{$\begin{array}{l}\text { Amount of } \\
\text { equipment and } \\
\text { tools*, pcs. }\end{array}$} & \multirow{2}{*}{$\begin{array}{c}\text { Number } \\
\text { of } \\
\text { posts } \\
f, \\
\text { units }\end{array}$} & \multirow{2}{*}{$\begin{array}{c}\begin{array}{c}\text { Number } \\
\text { of } \\
\text { workers } \\
u, \\
\text { persons }\end{array} \\
\text {, }\end{array}$} & \multicolumn{3}{|c|}{$\begin{array}{l}\text { Indexes of organizational } \\
\text { and technological } \\
\text { compatibility (OTC) } \\
\end{array}$} \\
\hline & $\begin{array}{c}Q_{A \max } \\
\text { for second line } \\
\text { maintenance }\end{array}$ & $\begin{array}{c}\stackrel{Q_{A \min }}{\text { for thirdline }} \\
\text { maintenance }\end{array}$ & $\boldsymbol{K}_{r 1}$ & $K_{r 6}$ & $\boldsymbol{K}_{r 7}$ & & & $\alpha$ & $\beta$ & $\gamma$ \\
\hline \multirow{5}{*}{ I } & 296 & 229 & \multirow{4}{*}{1} & \multirow{4}{*}{1} & \multirow{4}{*}{1} & \multirow{4}{*}{1} & 1 & 1 & 1 & 0,9553 \\
\hline & 562 & 440 & & & & & 2 & 1 & 1 & 0,5679 \\
\hline & 799 & 589 & & & & & 3 & 1 & 1 & 0,3978 \\
\hline & 896 & 625 & & & & & 4 & 1 & 1 & 0,235 \\
\hline & & for first se & vice $\mathrm{s}$ & ion in & enera & & & 1 & 1 & 0,5865 \\
\hline \multirow{5}{*}{ II } & 296 & 229 & \multirow{4}{*}{4} & \multirow{4}{*}{2} & \multirow{4}{*}{2} & \multirow{4}{*}{1} & 1 & 1 & 1 & 0,8262 \\
\hline & 593 & 458 & & & & & 2 & 1 & 1 & 0,5022 \\
\hline & 877 & 638 & & & & & 3 & 1 & 1 & 0,3809 \\
\hline & 1040 & 694 & & & & & 4 & 1 & 1 & 0,2612 \\
\hline & \multicolumn{7}{|c|}{ for second service station in general } & 1 & 1 & 0,5094 \\
\hline \multirow{9}{*}{ III } & 296 & 229 & \multirow{8}{*}{4} & \multirow{8}{*}{2} & & & 1 & 1 & 1 & 0,6696 \\
\hline & 605 & 464 & & & & & 2 & 1 & 1 & 0,4106 \\
\hline & 903 & 696 & & & & & 3 & 1 & 1 & 0,3232 \\
\hline & 1217 & 936 & & & 2 & 2 & 4 & 1 & 1 & 0,2915 \\
\hline & 1522 & 1118 & & & 2 & 2 & 5 & 1 & 1 & 0,2704 \\
\hline & 1739 & 1254 & & & & & 6 & 1 & 1 & 0,2149 \\
\hline & 1916 & 1335 & & & & & 7 & 1 & 1 & 0,1538 \\
\hline & 2049 & 1408 & & & & & 8 & 0,9957 & 0,9989 & 0,084 \\
\hline & & for third se & vice $s$ & ion i & ener: & & & 0,9998 & 0,9999 & 0,2967 \\
\hline & 296 & 229 & & & & & 1 & 1 & 1 & 0,5078 \\
\hline & 614 & 471 & & & & & 2 & 1 & 1 & 0,3077 \\
\hline & 915 & 704 & & & & & 3 & 1 & 1 & 0,2507 \\
\hline & 1217 & 932 & & & & & 4 & 1 & 1 & 0,229 \\
\hline JV & 1510 & 1156 & 4 & 2 & 2 & 3 & 5 & 1 & 1 & 0,2113 \\
\hline 10 & 1784 & 1344 & 4 & 2 & 2 & 3 & 6 & 1 & 1 & 0,1902 \\
\hline & 2049 & 1533 & & & & & 7 & 1 & 1 & 0,1666 \\
\hline & 2300 & 1656 & & & & & 8 & 1 & 1 & 0,1474 \\
\hline & 2493 & 1725 & & & & & 9 & 1 & 1 & 0,1082 \\
\hline & 2555 & 1815 & & & & & 10 & 0,9183 & 0,9614 & 0,046 \\
\hline & & for fourth $\mathrm{s}$ & rvice & tion & gener & & & 0,9959 & 0,9992 & 0,2065 \\
\hline & 296 & 229 & & & & & 1 & 1 & 1 & 0,3209 \\
\hline & 616 & 472 & & & & & 2 & 1 & 1 & 0,1798 \\
\hline & 920 & 706 & & & & & 3 & 1 & 1 & 0,1502 \\
\hline & 1224 & 936 & & & & & 4 & 1 & 1 & 0,1465 \\
\hline & 1522 & 1169 & & & & & 5 & 1 & 1 & 0,1422 \\
\hline & 1815 & 1389 & & & & & 6 & 1 & 1 & 0,1373 \\
\hline & 2090 & 1580 & 4 & $?$ & $?$ & 4 & 7 & 1 & 1 & 0,1307 \\
\hline V & 2379 & 1739 & 4 & 2 & 2 & 4 & 8 & 1 & 1 & 0,1235 \\
\hline & 2620 & 1934 & & & & & 9 & 0,9969 & 0,9997 & 0,1067 \\
\hline & 2797 & 2070 & & & & & 10 & 0,9986 & 0,9999 & 0,0916 \\
\hline & 3000 & 2178 & & & & & 11 & 0,9920 & 0,9998 & 0,0728 \\
\hline & 3136 & 2250 & & & & & 12 & 0,9078 & 0,9685 & 0,0445 \\
\hline & 3234 & 2325 & & & & & 13 & 0,4923 & 0,5841 & 0,0228 \\
\hline & 3338 & 2379 & & & & & 14 & 0,2595 & 0,283 & 0,0144 \\
\hline & & for fifth se & o & 1017 & CIncia & & & 0,9636 & $\mathbf{0 , 9 7 8 9}$ & 0,1191 \\
\hline
\end{tabular}


The system of OTC indicators includes coefficients of OTC $\alpha_{W}$, level of OTC $\beta_{W}$ and relative level of OTC $\gamma_{W}$, that are calculated for a particular value of the annual program $W_{A}$ min, provided, that any ratio of partial programs of orders for different types of technical maintenance in the total program of orders $W_{A} \min$ is equally probable.

Dependencies of OTC indicators of the technological processes of second and third line maintenance of tractors KhTZ-3522 in the joint technological flow on annual program $W_{A}$ min (by the number of orders for third line maintenance), received for the fifth variant of the production structure of the service station of the polytechnological specialization (Table 3), are shown in Figures 1-3.

These dependencies are discontinuous functions, intervals of continuity which coincide with the intervals of programs for the fifth variant of the production structure of the service station of the polytechnological specialization, where the number of workers $u$ remains unchanged (Figures 1-3).

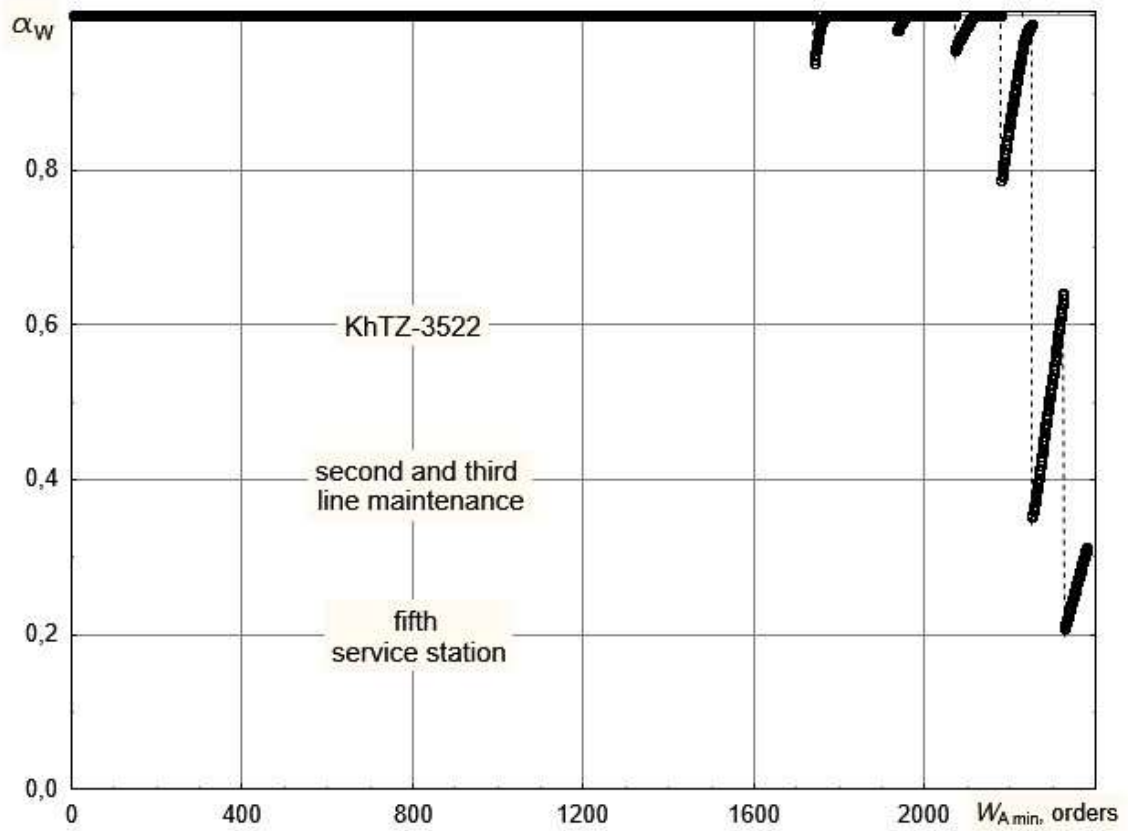

Fig. 1. Dependence of the coefficient of OTC $\alpha_{W}$ of second and third line maintenance of KhTZ-3522 tractors on the annual number of third line maintenance orders $W_{A}$ min for fifth service station.

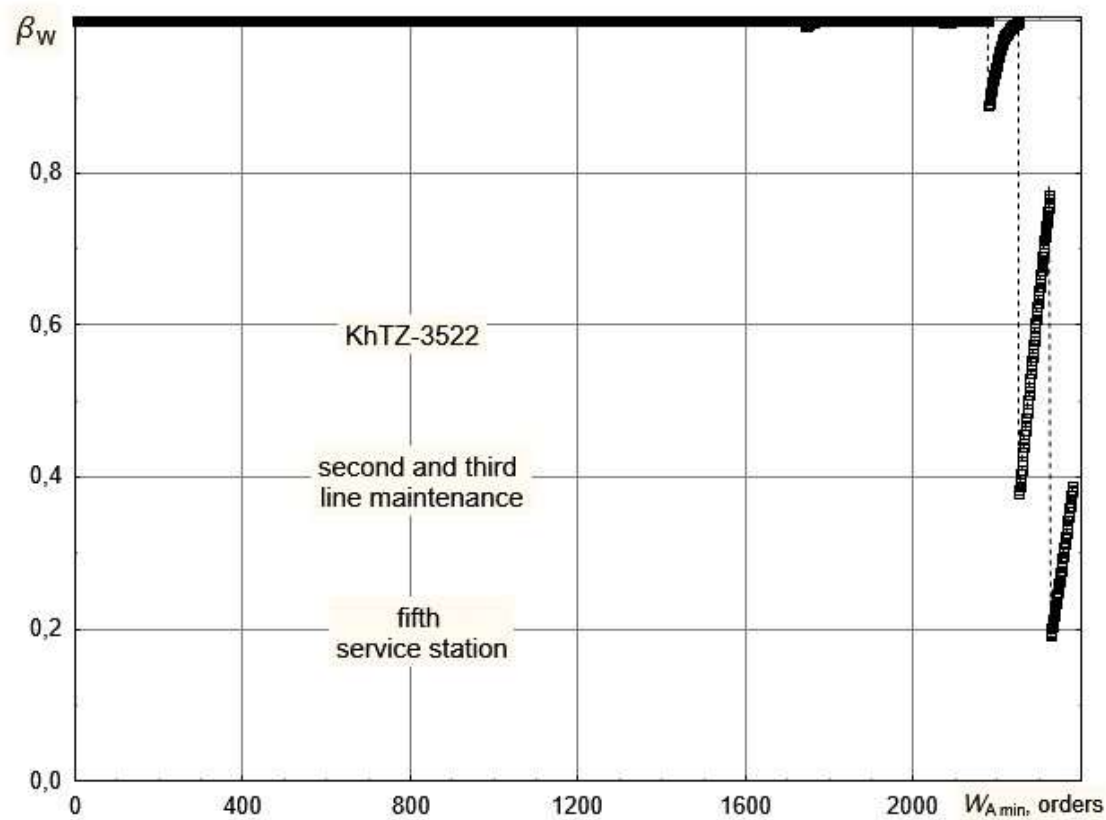

Fig. 2. Dependence of the coefficient of level of OTC $\beta_{W}$ of second and third line maintenance of KhTZ-3522 tractors on the annual number of third line maintenance orders $W_{A}$ min for fifth service station. 
As you can see (Figures 1-3) on the intervals of continuity, with the total annual program $W_{A \min }$ increasing, the values of the coefficient of OTC $\alpha_{W}$ and the coefficient of the level of OTC $\beta_{W}$ remain constant, provided that a complete OTC of technological processes of various types of maintenance in the joint technological flow is in evidence $\left(\alpha_{W}=\beta_{W}=1\right)$, or increases nonlinearly.
When the program $W_{A}$ min increases, the values of the coefficient of the relative level of $\mathrm{OTC}_{W}$ on the intervals of continuity remain constant or non-linearly increase even if a complete OTC of technological processes of various types of maintenance of tractors KhTZ-3522 $\left(\alpha_{W}=\beta_{W}=1\right)$ in a joint flow is in evidence.

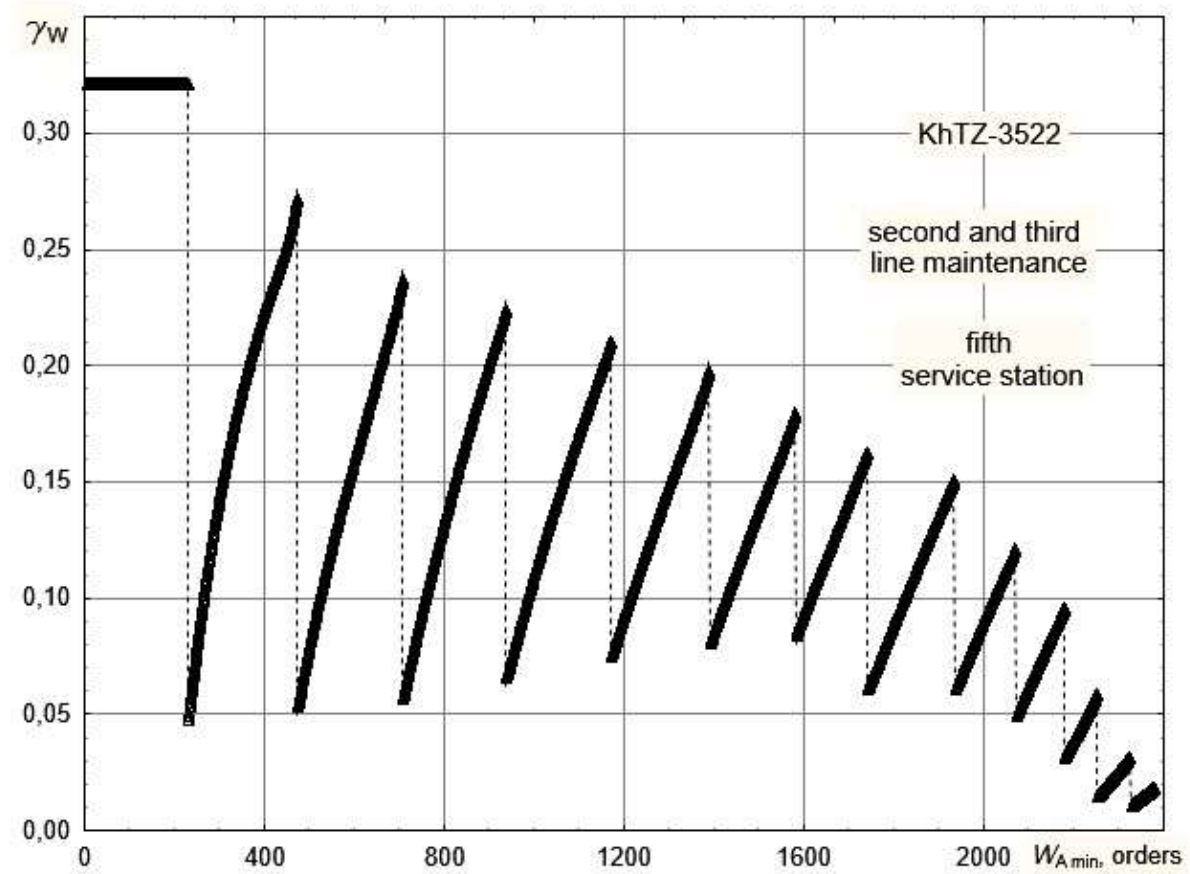

Fig. 3. Dependence of the coefficient of relative level of OTC $\gamma_{W}$ of second and third line maintenance of KhTZ-3522 tractors on the annual number of third line maintenance orders $W_{A}$ min for fifth service station.

The analysis of the results of calculating the values of OTC indicators of the technological processes of second and third line maintenance for service stations with different production structure and capacity from parametric series (Table 3), which was conducted under the additional condition that any values of the annual program $W_{A}$ min (by the annual number of third line maintenance orders), that are possible for a constant number of workers $u=$ const, are equally probable, allowed to reveal certain regularities.

Firstly, for each variant of the production structure of the service stations, with an increase in the number of workers, the values of OTC indexes do not increase. For example, for the third variant of the production structure of the service station, where the technological processes of the second and third line maintenance of tractors KhTZ-3522 are executed in the joint technological flow by two workers ( $u=2$ persons) $-\alpha=\beta=1,0$ and $\gamma=$ 0,4106 ; and when $u=8$ persons $-\alpha=0,9957, \beta=$ $0,9989, \gamma=0,084$ (Table 3).

Secondly, for service stations with a more complex production structure and higher capacity, the values of the OTC indicators are lower. For example, if for the third variant of the production structure of the service station in general $\alpha=0,9998, \beta=0,9999$ and $\gamma=0,2967$, then for fifth variant of the production structure of the service station in general $\alpha=0,9636, \beta=0,9789$ and $\gamma=$ $=0,1191$ (Table 3).

Thirdly, the most sensitive to the growth of the overall annual program of orders is the coefficient of the relative level of OTC $\gamma$.

At the same time, the obtained values of OTC indicators of the technological processes of second and third line maintenance in the joint flow for all five variants of production structures of service stations for tractors KhTZ-3522 designate the expediency of their polytechnological specialization.

\section{Conclusions}

1. The formed parametric series of production facilities of service stations for maintenance of KhTZ-3522 tractors both mono- and polytechnological specialization (Table 1-3) are the basis for the choice of the effective design solutions with following aspects to be taken into account: firstly, the forecast of annual changes in the total number of maintenance orders due to the changes in the number of these tractors in the service area, and, secondly, the prediction of seasonal fluctuations in the 
flow of orders due to the objective variation of use of these tractors in agriculture.

2. The obtained values of OTC of the technological processes of second and third line maintenance in the joint technological flow for all five variants of production structures of the service stations for maintenance of KhTZ-3522 tractors give reasons for the polytechnological specialization of such items.

\section{References}

1. Process flow charts of pre-sales service and maintenance of KhTZ-3512, KhTZ-3522 tractors, Kharkov Tractor Plant named after S. Ordzhonikidze, p. 80 (2014)

2. Tractor KhTZ-3512. Operating instructions. 3512.00.001, Kharkov Tractor Plant named after S. Ordzhonikidze, p. 46 (2014)

3. M.V. Molodyk, A.M. Morgun, L.I. Shapoval at all, Organizational forms of technical service and forecast of their development in market conditions of management in the agroindustrial complex of Ukraine. Recommendations, National Scientific Center «Institute of Mechanization and Electrification of Agriculture», p. 170 (2001)

4. O.V. Sydorchuk, S.R. Senchuk, O.V. Kukharuk, Scientific bases of engineering management of technical service of crop farming, Monograph, $\mathrm{p}$. 172 (2001)

5. A. Bailey, N. Williams, M. Palmer, R. Geering, AGRICULTURAL SYSTEMS, The farmer as service provider: the demand for agricultural commodities and equine services, 3 (66), 191-204 (2000)

6. S. Juściński, W. Piekarski, Maintenance and Reliability, The farm vehicles operation in the aspect of the structure of demand for maintenance inspections, 1 (45), 59-68 (2010)

7. O.D. Semkovych, R.D. Kuzminskyj, V.E. Chukhrai, M.S. Oliskevych, News of Agrarian Sciences, Formation and development of the theory of repair and recovery processes, Special issue, September, 90-96 (2001)

8. R.D. Kuzminskyj, Bulletin of Lviv State Agrarian University: Agroengineering research, Structure, parameters and efficiency of technological processes of repair, 9, 50-60 (2005)

9. V.O. Tymochko. Dis. Cand. Tech. Sciences: 05.20.03, Effective production structure of technological stations of current repairs of tractors of classes 0,9 and 1,4, p. 241 (1994)

10. R.D. Kuzminskyj, R.I. Barabash, Bulletin of Lviv State Agrarian University: Agroengineering research, Parameters and performance indicators of technological processes of technical service performed on stationary posts, 10, 66 - 73 (2006)

11. O.V. Sydorchuk, R.D. Kuzminskyj, R.I. Barabash, M.A. Mykhajluk, Bulletin of Lviv National Agrarian University: Agroengineering research, Justification of production structure of service stations for maintenance of KhTZ tractors, 17, 5464 (2013)

12. R.D. Kuzminskyj, R.I. Barabash, Scientific discussion: Issues of technical sciences, The results of modeling of technological processes of maintenance of KhTZ-3522 tractors, 4 (25), 97-107 (2015)

13. R.D. Kuzminskyj, Agricultural machines. Collection of scientific articles, An organizational and technological compatibility of different objects repair processes in joint technological flow as the basis of formation of thefirm technical service, 14, 114-124 (2006)

14. R.D. Kuzminskyj, Theory and practice of development of the agro-industrial complex: Materials of the international scientific and practical forum, An improvement of the indicators system of organizational and technological compatibility of different objects repair processes in joint technological flow, 2, 354-359 (2006).

15. R.D. Kuzminskyj, I.G. Stukalec. Ecological, technological and socio-economic aspects of the use of material and technical base of the agro-industrial complex: Materials of the international scientific and practical forum. Calculation of the indicators of organizational and technological compatibility of different objects repair processes for single tact value, 406-409 (2008) 